\title{
Dejetos líquidos de suínos como alternativa a adubação mineral na cultura do milho
}

\section{Pig slurry as an alternative to mineral fertilizer in maize crop}

\author{
Moacir Tuzzin de Moraes ${ }^{1}$; Fernando Arnuti ${ }^{1}$; Vanderlei Rodrigues da Silva ${ }^{2 *}$; \\ Rodrigo Ferreira da Silva²; Claudir José Basso²; Clovis Orlando Da Ros²
}

\section{Resumo}

A utilização de dejeto líquido de suínos (DLS) como fonte de nutrientes no cultivo de grãos como o milho, pode ser uma opção para o destino destes resíduos orgânicos produzidos em grandes quantidades nas granjas suinícolas, possibilitando assim substituição total ou parcial da adubação mineral nos cultivos agrícolas. O objetivo desse trabalho foi avaliar a utilização de DLS como substituição a adubação mineral na cultura do milho em condições de um Latossolo Vermelho, muito argiloso. Os tratamentos consistiram na utilização de adubação mineral recomendada para a cultura do milho; sem adubação; e doses de DLS $\left(25 ; 50 ; 75 ; 100 \mathrm{~m}^{3} \mathrm{ha}^{-1}\right)$. Foram avaliadas as variáveis: comprimento e diâmetro da espiga, número de grãos por espiga, peso de mil grãos e produtividade de grãos. As maiores produtividades de grãos foram obtidas com a adubação mineral e doses de 50, 75 e $100 \mathrm{~m}^{3} \mathrm{ha}^{-1}$ de DLS. A adubação mineral na cultura do milho pode ser substituída por doses de DLS a partir de $50 \mathrm{~m}^{3} \mathrm{ha}^{-1}$, sem que haja prejuízos na produtividade da cultura do milho em um Latossolo Vermelho de textura muito argilosa.

Palavras-chave: Zea mays, adubação orgânica, produção de grãos, suinocultura

\begin{abstract}
The use of swine residue (SR) as a source of nutrients in growing crops such as maize, may be an option for disposal of organic waste produced in large quantities in pig farms, allowing total or partial substitution of mineral fertilizer in agricultural crops. The objective of this study was to enable the use of SR as an alternative source of nutrients to the mineral fertilization in maize under conditions of a Rhodic Hapludox. The treatments consisted of the use of mineral fertilizer recommended for maize; no fertilization (control), and doses of SR $\left(25,50,75,100 \mathrm{~m}^{3} \mathrm{ha}^{-1}\right)$. The variables: length and ear diameter, number of grains per spike, thousand grain weight and yield. The highest grain yields were obtained with chemical fertilizers and doses of 50,75 and $100 \mathrm{~m}^{3} \mathrm{ha}^{-1}$ of SR. The mineral fertilization in maize can be replaced by doses of SR from $50 \mathrm{~m}^{3} \mathrm{ha}^{-1}$, with no loss in productivity of maize in a Rhodic Hapludox with very clayey texture.
\end{abstract}

Key words: Zea mays, organic fertilizer, grains yield, pig's farming

\footnotetext{
${ }^{1}$ Eng $^{\text {os }}$ Agros, Mestres, Discentes do Curso de Doutorado do Programa de Pós Graduação em Ciência do Solo, Universidade Federal do Rio Grande do Sul, UFRGS, Porto Alegre, RS. E-mail: moacir.tuzzin@gmail.com; fernando.arnuti@gmail.com

${ }^{2}$ Eng $^{\text {os }}$ Agr $^{\text {os }}$, Profs. Drs., Dept ${ }^{\circ}$ de Ciências Agronômicas e Ambientais, Universidade Federal de Santa Maria, campus de Frederico Westphalen, UFSM, Frederico Westphalen, RS. E-mail: vanderlei@ufsm.br; rofesil@bol.com; claudirbasso@gmail. com; clovisdaros@gmail.com

* Autor para correspondência
} 


\section{Introdução}

A utilização dos dejetos líquidos de suínos (DLS) na fertilização do solo tem sido praticada e difundida por ser fonte de nutrientes para as plantas, principalmente de nitrogênio, fósforo e potássio, além de ser uma forma de descarte e destinação deste resíduo da criação de suínos. A busca de novas fontes de nutrientes para as culturas se reforça em função do aumento nos custos de produção dos fertilizantes químicos que contém nitrogênio, fósforo, potássio ou enxofre. Pois, ao longo do tempo, poderá haver aumentos nestes custos à medida que os materiais que são extraídos com maior facilidade forem consumidos (FIXEN, 2009). Portanto, a necessidade de obter fontes alternativas de nutrientes para as culturas com menor custo de produção tem estimulado a utilização do DLS como fonte de nutrientes em potencial para as culturas de interesse agronômico (p. ex. soja, milho, trigo, feijão, entre outras). Entretanto, a maior parte dos dejetos de suínos gerados nas unidades de produção são manejados, armazenados e distribuídos na forma líquida (GIACOMINI; AITA, 2008), o que acarreta em maiores custos e cuidados na aplicação. Por isso, ambientalmente o DLS pode se tornar um poluente se o seu uso não respeitar a capacidade de absorção do solo e a necessidade das culturas (CERETTA et al., 2010). Para isso, deve ser considerada a resistência aos impactos ambientais estabelecidos para as diferentes classes de solos que ocorrem no RS e os limites baseados nas características físicas, mineralógicas e aptidões dos solos (KAMPF et al., 2008).

Os DLS contêm matéria orgânica, nitrogênio, fósforo, potássio, cálcio, sódio, magnésio, manganês, ferro, zinco, cobre e outros elementos incluídos nas dietas dos animais (SERPA FILHO et al., 2013). Entretanto, agronomicamente, os DLS podem ser considerados um fertilizante não balanceado, uma vez que é difícil ajustar as diferenças entre as necessidades das plantas (quantitativa e temporalmente) e a oferta dos nutrientes (BERWANGER; CERETTA; SANTOS,
2008). A baixa concentração de nutrientes dos adubos orgânicos pode ser um impedimento a sua utilização devido à necessidade de aplicação de volumes maiores, quando comparado a fertilizantes minerais, para suprir a mesma quantidade de nutrientes. A matéria orgânica presente nos DLS é predominantemente composta por carbono orgânico lábil, o qual é rapidamente mineralizada no solo (ANGERS et al., 2010), elevando a disponibilidade de macro e micronutrientes no solo. Desta forma, a incorporação de matéria orgânica nos solos, na forma de esterco animal ou de compostos orgânicos, aumenta a capacidade de troca catiônica e proporciona a melhoria na estrutura, caracterizada pela diminuição da densidade do solo, aumento da porosidade e da taxa de infiltração de água (SEDIYAMA et al., 2000). Além disso, melhorias na distribuição do tamanho de poros do solo poderão favorecer incrementos no armazenamento de água no perfil, prolongando o período com adequada disponibilidade hídrica para as culturas.

A preocupação com o descarte dos DLS torna-se cada vez maior, especialmente aqueles resultantes do sistema de produção de suínos em regime de confinamento. A melhor alternativa de disposição está relacionada à utilização dos mesmos como fontes de nutrientes em cereais de inverno (YAGÜE; QUIILEZ, 2010; CELA; SANTIVERI; LIOVERAS, 2011), nas culturas de verão (GIACOMINI et al., 2009; LEITE; CUNHA NETO; RESENDE, 2009) e nas pastagens (BARNABÉ et al., 2007). Ceretta et al. (2003) avaliando as alterações das características químicas de um solo sob pastagem natural e suas implicações agronômicas e ambientais com a utilização de DLS, observaram que uso sistemático deste material representa a adição de grande quantidade de nutrientes ao solo, e eleva principalmente os teores de $\mathrm{P}, \mathrm{Ca}$ e $\mathrm{Mg}$, além de favorecer a diminuição da saturação de alumínio, melhorando assim o ambiente de crescimento das plantas. Aita, Port e Giacomini (2006) avaliando a dinâmica do nitrogênio no solo e produção de fitomassa por plantas de cobertura no 
outono/inverno com aplicação de DLS, observaram que estes apresentaram elevado potencial como fertilizante, visto que o seu uso aumentou o acúmulo de nutrientes e a produção de matéria seca das plantas de cobertura.

A necessidade nutricional das plantas é um fator que deve ser considerado quando o objetivo é aumentar a produção de grãos (VON PINHO et al., 2009). O milho responde progressivamente à adubação desde que os demais fatores determinantes da produtividade estejam em níveis ótimos, normalmente, os agricultores que obtêm altas produtividades de grãos de milho, aplicam altas doses de fertilizantes, geralmente acima dos níveis recomendados em suas regiões (CERETTA et al., 2010). Normalmente em lavouras de alto rendimento de grãos de milho (acima de 12 a $13 \mathrm{Mg} \mathrm{ha}^{-1}$ ) a adoção conjunta de cultivares melhoradas, insumos e técnicas de cultivo adequadas faz com que estes rendimentos sejam mais elevados (MUNDSTOCK; SILVA, 2005). Portanto, o nitrogênio é o nutriente que apresenta maior resposta de aumento de produtividade de grãos (KAPPES et al., 2009; SEIDEL et al., 2010) e conforme a CQFS-RS/SC (2004), a partir de $4 \mathrm{Mg} \mathrm{h}^{-1}$, a cultura do milho necessita de $15 \mathrm{~kg} \mathrm{ha}^{-1}$ de nitrogênio, por tonelada adicional de grãos a serem produzidos. Sendo assim, o nitrogênio se torna muito importante, pois é o nutriente encontrado em maior proporção nos DLS (BASSO et al., 2004).

Neste contexto, o objetivo desse trabalho, foi avaliar a utilização de DLS como substituição a adubação mineral, na cultura do milho, em condições de um Latossolo Vermelho de textura muito argilosa.

\section{Material e Métodos}

O trabalho foi realizado, no ano agrícola de 2009/10, na área experimental da Universidade Federal de Santa Maria, campus de Frederico Westphalen - RS, cuja localização é, latitude 27039' S; longitude $53^{\circ} 42^{\prime} \mathrm{W}$ e altitude $490 \mathrm{~m}$, município de Frederico Westphalen. O solo, manejado sob sistema plantio direto desde o ano de 2000, possui textura muito argilosa, é classificado como Latossolo Vermelho Aluminoférrico típico (SANTOS et al., 2013). As características físicas e químicas da camada superficial do solo $(0,0-0,10 \mathrm{~m})$, antes da implantação do experimento, são apresentadas na tabela 1 .

Tabela 1. Características químicas e teor de argila do solo utilizado no experimento. Frederico Westphalen, RS, UFSM.

\begin{tabular}{|c|c|c|c|c|c|c|c|c|c|c|c|c|c|}
\hline pH água & SMP & $\mathrm{P}$ & $\mathrm{K}$ & $\mathrm{Al}$ & $\mathrm{Ca}$ & $\mathrm{Mg}$ & $\mathrm{Cu}$ & $\mathrm{Zn}$ & $\mathrm{H}+\mathrm{Al}$ & M.O. & Argila & $\mathrm{m}$ & V \\
\hline ---1:1--- & & \multicolumn{2}{|c|}{$--\mathrm{mg} \mathrm{dm}{ }^{-3}--$} & \multicolumn{6}{|c|}{--o---- $\mathrm{Cmol} \mathrm{dm}^{-3}$} & \multicolumn{4}{|c|}{-------------- } \\
\hline 5,1 & 6,2 & 7,6 & 280 & 0,2 & 5,5 & 1,6 & 5,8 & 1,8 & 3,2 & 2,1 & 65,0 & 2,5 & 69,0 \\
\hline
\end{tabular}

P- fósforo disponível; K - potássio disponível; Al- Alumínio trocável; Ca- cálcio trocável; Mg- magnésio trocável; Cu - cobre disponível; Zn- zinco disponível; M.O.: matéria orgânica; $\mathrm{m}$ - saturação por alumínio; V- saturação por bases.

Fonte: Elaboração dos autores.

O clima dessa região, segundo a classificação de Koppen, é subtropical úmido sem estiagens, tipo Cfa (MOTA, 1981). A precipitação ocorrida durante a condução do experimento foi uniforme, totalizando $1.202 \mathrm{~mm}$.

O delineamento experimental utilizado foi de blocos completos casualizados (DBC) com seis tratamentos e quatro repetições. Utilizaramse parcelas com área de $12,5 \mathrm{~m}^{2}$ (5 x 2,5 m). Os tratamentos foram doses de 25, 50, 75 e $100 \mathrm{~m}^{3} \mathrm{ha}^{-1}$ de DLS, além de dois tratamentos controles, um sem adubação (zero), e um com adubação mineral de nitrogênio $(\mathrm{N})$ fósforo $(\mathrm{P})$ e potássio $(\mathrm{K})$. O DLS foi aplicado manualmente nas parcelas logo após a 
semeadura do milho. Considerando que os principais nutrientes encontrados no DLS são o nitrogênio, o fósforo e o potássio, Scherer, Baldissera e Dias (1995), indicam a determinação da concentração destes nutrientes em função da densidade e teor de matéria seca (MS) do DLS. Portanto, o DLS utilizado apresentou densidade de $1.013 \mathrm{~g} \mathrm{~kg}^{-1}$, correspondendo a MS: 2,32\%; $\mathrm{N}: 2,37 \mathrm{~kg} \mathrm{~m}^{-3}, \mathrm{P}_{2} \mathrm{O}_{5}$ : $1,90 \mathrm{~kg} \mathrm{~m}^{-3}$; e $\mathrm{K}_{2} \mathrm{O}: 1,31 \mathrm{~kg} \mathrm{~m}^{-3}$. O teor de nutrientes do DLS (Tabela 2) foi calculado em função de sua densidade, correlacionando os valores de MS e com os respectivos teores de nutrientes (SCHERER; BALDISSERA; DIAS, 1995). A adubação mineral foi realizada, conforme recomendação da CQFSRS/SC (2004), com expectativa de rendimento de grãos de $6 \mathrm{Mg} \mathrm{ha}^{-1}$. Foi aplicado na semeadura 45 $\mathrm{kg} \mathrm{ha} \mathrm{h}^{-1}$ de ureia (equivalente em $\mathrm{N}$ : $20 \mathrm{~kg} \mathrm{ha}^{-1}$ ), $183 \mathrm{~kg} \mathrm{ha}^{-1}$ de superfosfato triplo (equivalente em $\mathrm{P}_{2} \mathrm{O}_{5}: 77 \mathrm{~kg} \mathrm{ha}^{-1}$ ) e $45 \mathrm{~kg} \mathrm{ha}^{-1}$ de cloreto de potássio (equivalente em $\mathrm{K}_{2} \mathrm{O}: 27 \mathrm{~kg} \mathrm{ha}^{-1}$ ) e, trinta dias após a emergência foi aplicado, em cobertura, $205 \mathrm{~kg} \mathrm{ha}^{-1}$ de ureia (equivalente em N: $90 \mathrm{~kg} \mathrm{ha}^{-1}$ ) (Tabela 2).

Tabela 2. Teores de nutrientes presentes na adubação mineral e nas doses de dejetos líquidos de suínos (DLS). Frederico Westphalen, RS, 2014.

\begin{tabular}{|c|c|c|c|c|c|c|}
\hline \multirow{2}{*}{ Nutriente } & \multirow{2}{*}{ Adubação mineral } & \multicolumn{5}{|c|}{ - Doses de DLS $\left(\mathrm{m}^{3} \mathrm{ha}^{-1}\right)$} \\
\hline & & zero & 25 & 50 & 75 & 100 \\
\hline & & -- & $\mathrm{kg} \mathrm{ha}$ & 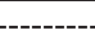 & ---- & \\
\hline $\mathrm{N}$ & 110,0 & - & 59,2 & 118,5 & 177,7 & 237,0 \\
\hline $\mathrm{P}_{2} \mathrm{O}_{5}$ & 76,9 & - & 47,5 & 95,0 & 142,5 & 190,0 \\
\hline $\mathrm{K}_{2} \mathrm{O}^{3}$ & 27,0 & - & 32,7 & 65,5 & 98,2 & 131,0 \\
\hline
\end{tabular}

$\mathrm{N}$ : Nitrogênio disponível; $\mathrm{P}_{2} \mathrm{O}_{5}$ : fósforo disponível; $\mathrm{K}_{2} \mathrm{O}$ : Potássio disponível.

Fonte: Elaboração dos autores.

O cultivar de milho utilizado foi o híbrido simples AS-1578 YG (tecnologia YieldGard®) de ciclo precoce. O controle de plantas daninhas foi realizado para todas as parcelas através de capina manual. O espaçamento entre as linhas de milho foi de $0,40 \mathrm{~m}$, com população final de 65 mil plantas ha $^{-1}$. Cada parcela possuía dez linhas de $5 \mathrm{~m}$ de comprimento, sendo utilizadas como área útil as cinco linhas centrais desconsiderando $0,50 \mathrm{~m}$ das extremidades e colhendo as plantas do centro da parcela (área útil de $8 \mathrm{~m}^{2}$ ).

$\mathrm{Na}$ colheita, avaliaram-se na área útil de cada parcela as seguintes variáveis explicativas (componentes de rendimento): i) Comprimento de espiga (CEsp): através da distância entre o primeiro e o último grão da linha mais longa, medida com um paquímetro digital; ii) Diâmetro de espiga (DEsp): medido no centro da espiga antes da debulha dos grãos com um paquímetro digital; iii) Peso de mil grãos (PMG): contagem de oito repetições de 100 grãos, corrigindo a umidade para $13 \%$ e calculando o peso de mil grãos através da equação (1), e expresso em gramas, conforme as Regras de Análises de Sementes - RAS (BRASIL, 2009); iv) Número de grãos por espiga (NGEsp): foi determinado pela equação (2).

Peso de mil grãos $(\mathrm{PMG})=$ peso da amostra $\mathrm{x} 1000$ $/ \mathrm{n}^{\mathrm{o}}$ total de sementes (1)

Número de grãos por espiga (NGEsp) = (peso total*1000) / (PMG* $\mathrm{N}^{\mathrm{o}}$ espigas) (2)

Onde: peso total: peso total dos grãos da parcela; PMG: peso de mil grãos; $\mathrm{N}^{o}$ espiga: número de espigas na parcela.

A variável básica ou dependente, no caso, a produtividade de grãos, foi determinada pesando-se os grãos das espigas colhidas na área útil $\left(8 \mathrm{~m}^{2}\right)$, no centro da parcela, corrigidos a $13 \%$ de umidade (BRASIL, 2009). 
Os resultados foram submetidos à análise de variância (Teste $\mathrm{F}, \mathrm{p}<0,05$ ), e quando significativos submetidos à análise de regressão, para os fatores quantitativos (doses de DLS). Para os fatores qualitativos (comparação das doses de DLS com a adubação mineral e com a testemunha sem adubação) realizou-se o teste de médias por contrastes ortogonais, a $5 \%$ de probabilidade de erro.

\section{Resultados e Discussão}

A utilização de DLS e adubação mineral influenciaram as variáveis explicativas dos componentes de rendimento da cultura do milho, sendo que estas correlacionaram com a variável dependente (produtividade de grãos). A maioria das variáveis apresentou incremento significativo em função do aumento de doses de DLS. Resultados semelhantes foram observados por Rambo et al. (2008), comparando alguns componentes do rendimento do milho e doses de nitrogênio em um Argissolo Vermelho Distrófico.

O comprimento de espiga foi alterado com o incremento de doses de DLS revelando aumento quadrático, sendo que as doses 50, 75 e $100 \mathrm{~m}^{3}$ $\mathrm{ha}^{-1}$ foram significativamente superiores as demais doses (Figura 1a). Além disso, a dose de $100 \mathrm{~m}^{3}$ $\mathrm{ha}^{-1}$ proporcionou maior comprimento de espiga em relação à adubação mineral. Kappes et al. (2009) observaram que o comprimento das espigas foi alterado em função da aplicação de N, em relação á testemunha sem aplicação de N. Estes autores, também afirmam que o comprimento de espiga apresenta relação positiva com a produtividade de grãos. Neste sentido, o incremento no comprimento de espiga, poderá ter influenciado positivamente os resultados de rendimento de grãos, concordando com incrementos lineares de produtividade de grãos observados por Sartor et al. (2012) em um Latossolo Vermelho na Região de Pato Branco/PR. Conforme Lopes et al. (2007) o comprimento de espiga está correlacionado com o peso de grãos das espigas devido ao efeito indireto do peso de cem grãos e do número de grãos por espiga, indicando assim, que o incremento do comprimento das espigas, proporcionado pelo número e tamanho dos grãos, poderá incrementar o rendimento de grãos da cultura do miho.

A variável diâmetro de espiga (Figura 1b) apresentou incremento linear em função do aumento nas doses de DLS. Desta forma, o diâmetro de espiga, refletiu a capacidade produtiva da planta em formação de maior quantidade de grãos. Conforme Mundstock e Silva (2005) o aumento do número de grãos por espiga pode ser um dos principais fatores responsáveis pelo incremento do potencial de rendimento de grãos de milho. Sendo que o diâmetro das espigas nos tratamentos com doses acima de $50 \mathrm{~m}^{3} \mathrm{ha}^{-1}$ de DLS, não diferiram dos valores de diâmetros de espigas obtidos com uso de adubação mineral. Indicando assim que a substituição da adubação mineral por DLS poderá ser realizada sem que ocorram reduções no potencial produtivo da cultura de milho. Considerando que, em híbridos simples de milho, o comprimento e o diâmetro das espigas atuam diretamente para o aumento do peso de grãos (LOPES et al., 2007), pode-se observar que a utilização de DLS favorece os principais componentes de rendimento que atuarão no aumento da produtividade de grãos da cultura do milho.

O tratamento com adubação mineral e a dose de $100 \mathrm{~m}^{3}$ ha $^{-1}$ não diferenciaram significativamente e apresentaram peso de mil grãos superior as demais doses de DLS (Figura 1c). Os valores do peso de mil grãos obtidos no trabalho foram superiores aos encontrados por Bortolini et al. (2001) avaliando aplicação de $\mathrm{N}$ em pré-semeadura. $\mathrm{O}$ peso de mil grãos obteve incremento linear em função do aumento das doses de DLS. Conforme Lopes et al. (2007) presença de espigas com maiores peso de mil grãos e maior número de grãos tem efeito direto sobre a produtividade de grãos. A extração de nitrogênio, fósforo, potássio, cálcio e magnésio aumenta linearmente com o aumento na produção, e que a maior exigência do milho 
refere-se a nitrogênio e potássio, seguindo-se cálcio, magnésio e fósforo (COELHO; FRANÇA, 1995). Neste sentido, a maior oferta nutricional aportada pelo incremento de doses de DLS poderá ter favorecido melhorias nutricionais no solo para o desenvolvimento da cultura do milho. A absorção máxima de nitrogênio e fósforo pela cultura do milho ocorre durante as fases de desenvolvimento vegetativo e reprodutivo (COELHO; FRANÇA, 1995). Queiroz et al. (2011) observaram incrementos lineares de produtividade de grãos em função do aumento de doses de nitrogênio, indicando assim que o nitrogênio favorece a formação dos grãos de milho, desde que os demais nutrientes não sejam limitantes, a aplicação de DLS (que apresenta grande quantidade de nitrogênio) poderá melhorar o desempenho produtivo da cultura do milho. Além disso, o aumento da oferta de nitrogênio pode prolongar o período de retranslocação de açúcares e nitrogênio para os grãos, aumentando assim o peso de mil grãos (FERREIRA et al., 2001). O aumento da disponibilidade de fósforo e potássio, em função do incremento das doses de DLS, possivelmente favoreceu maiores translocações destes nutrientes para os grãos. Conforme Ferreira et al. (2001) a maior disponibilidade nutricional favorece aumentos da produção de grãos, pois, está diretamente relacionada com o maior transporte de armazenamento de fotoassimilados nos grãos.

Figura 1. Componentes do rendimento da cultura do milho em função de doses de dejetos líquidos de Suínos (DLS) e adubação mineral. a) Comprimento espiga ( $\mathrm{cm})$; b) Diâmetro de espiga $(\mathrm{mm})$; c) Peso de mil grãos (g); e d) Número de grãos por espiga (Unid.). Frederico Westphalen, RS, 2014. * Médias seguidas da mesma não diferem entre si pelo teste de contrastes ortogonais a $5 \%$ de probabilidade de erro.

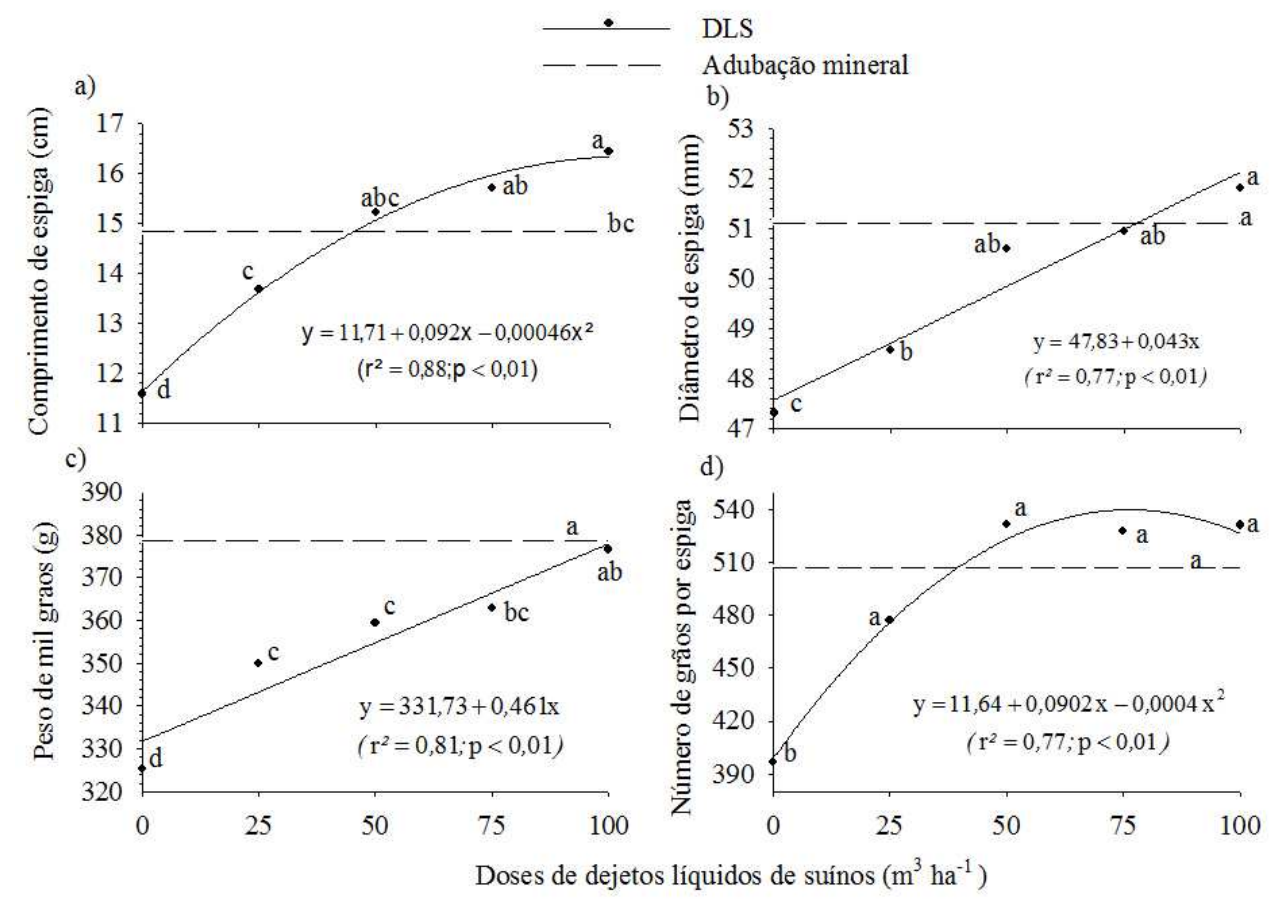

Fonte: Elaboração dos autores. 
A média de grãos por espiga foi de 495 grãos, onde os tratamentos demonstraram uma equação quadrática em função das doses DLS (Figura 1d). Os tratamentos, com a adubação mineral e as doses de DLS a partir de $25 \mathrm{~m}^{3}$ ha $^{-1}$ não diferiram entre si e, foram superiores a testemunha sem adubação. Bortolini et al. (2001), avaliando aplicação de nitrogênio aplicado na pré-semeadura, sob condições adequada e excessiva disponibilidade hídrica, também encontraram resultados semelhantes, indicando efeito do N presente nos DLS na nutrição das plantas.

Aprodutividade de grãos de milho foi influenciada pelas doses de DLS, sendo que ocorreram diferenças significativas $(p<0,05)$ no rendimento dos grãos obtido pelas doses de DLS quando comparadas com a testemunha sem adubação (Figura 2). A máxima eficiência técnica de produtividade de grãos foi obtida como uso de $91 \mathrm{~m}^{3} \mathrm{ha}^{-1}$ de DLS. Sendo que a partir de $50 \mathrm{~m}^{3} \mathrm{ha}^{-1}$ de DLS não houve diferenças entre as doses de DLS e a adubação mineral. Neste sentido, a substituição da adubação mineral, sem haver perdas produtivas de grãos na cultura de milho, pode ser realizada por doses a partir de 50 $\mathrm{m}^{3}$ ha $^{-1}$ de DLS, Entretanto, a partir de $91 \mathrm{~m}^{3} \mathrm{ha}^{-1}$ de DLS não houve incrementos na produtividade de grãos de milho. Considerando assim, esta faixa entre 50 e $91 \mathrm{~m}^{3} \mathrm{ha}^{-1}$ de DLS como sendo adequada para a cultura do milho neste Latossolo Vermelho. Todos os tratamentos foram superiores a testemunha sem adubação. A produtividade de grãos de milho no tratamento com $25 \mathrm{~m}^{3} \mathrm{ha}^{-1}$ foi de $9.917 \mathrm{~kg} \mathrm{ha}^{-1}$, diferindo significativamente da testemunha sem adubação, que produziu $8.488 \mathrm{~kg}$ ha $^{-1}$ (Figura 2). Giacomini et al. (2004) avaliando o potencial de utilização do DLS, em um Argissolo Vermelho, associado a plantas de cobertura de solo de inverno sobre o milho cultivado em sucessão sob plantio direto, observaram que o DLS mostrou-se uma alternativa eficiente como fonte de nutrientes ao milho, aumentando o acúmulo de nutrientes, a produtividade de matéria seca e o rendimento de grãos, proporcionalmente ao aumento nas doses de dejetos utilizadas.

$\mathrm{O}$ incremento de produtividade de grãos (Tabela 3) ocorreu com doses a partir de $25 \mathrm{~m}^{3} \mathrm{ha}^{-1}$ de DLS em relação ao tratamento sem adubação. De modo geral, todas as doses de DLS proporcionaram incrementos significativos de produção de grãos em relação à testemunha sem adubação. Com a dose de $25 \mathrm{~m}^{3} \mathrm{ha}^{-1}$, o incremento de rendimento, em relação a testemunha sem adubação foi de 1.429 $\mathrm{kg} \mathrm{ha}^{-1}$, ou seja, $17 \%$ de aumento de produção, já para a dose de $50 ; 75$ e $100 \mathrm{~m}^{3} \mathrm{ha}^{-1}$ o incremento foi de $49 \% ; 45 \%$ e $52 \%$, respectivamente, variando de 3.850 a $4.411 \mathrm{~kg} \mathrm{ha}{ }^{-1}$. A adubação mineral proporcionou incremento de $48 \%$ na produtividade quando comparada a testemunha (sem adubação), demonstrando a necessidade de utilização de uma fonte de nutrientes para o bom desenvolvimento e produtividade da cultura do milho nas condições deste solo em estudo.

Comparando a produtividade de grãos dos tratamentos com a adubação mineral, observa-se que somente a testemunha $(-32,59 \%)$ e a dose de $25 \mathrm{~m}^{3}$ ha $^{-1}$ de DLS (-21,23\%) apresentaram redução de produtividade de grãos. Resultados semelhantes foram encontrados por Sartor et al. (2012) cultivando milho, em um Latossolo Vermelho muito argiloso no Norte do Paraná. Estes autores observaram, que o uso de $60 \mathrm{~m}^{3} \mathrm{ha}^{-1}$ de DLS, favorece a obtenção dos maiores rendimentos de grãos de gramíneas, neste sentido, além de ser uma forma de descarte do DLS resultante da atividade suinícola, contribui para aumento significativo no rendimento de grãos, substituindo assim o fertilizante mineral. 
Figura 2. Produtividade de grãos da cultura do milho obtido com adubação mineral (NPK) e doses de dejetos líquidos de suínos. Frederico Westphalen, RS, 2014. *Médias seguidas por mesma letra não diferem entre si, pelo teste de contrastes ortogonais a 5\% de significância.

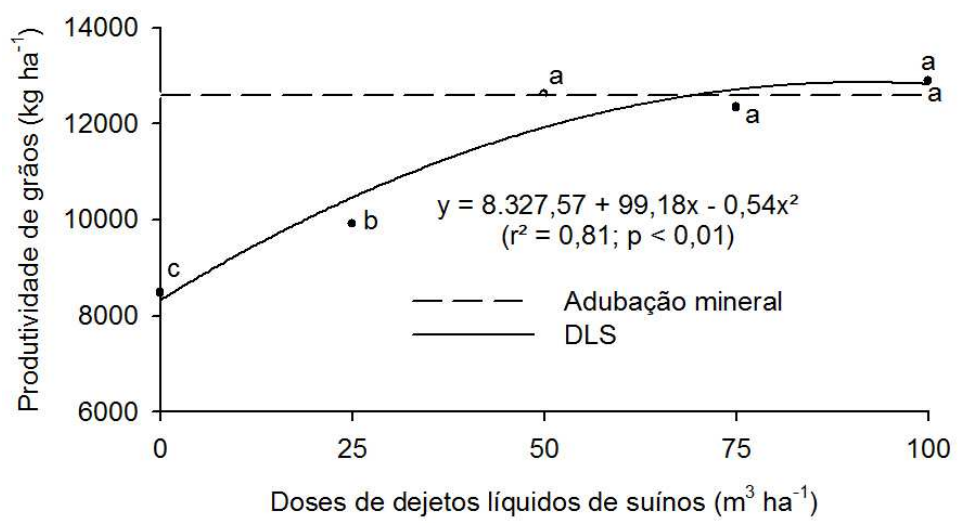

Fonte: Elaboração dos autores.

Tabela 3. Contrastes ortogonais das médias de produtividade de grãos e do incremento de produtividade de grãos de milho sob adubação com doses de dejetos líquidos de suínos $\left(25 ; 50 ; 75 ; 100 \mathrm{~m}^{3} \mathrm{ha}^{-1}\right)$, em relação a testemunha sem adubação (zero) e adubação mineral (NPK) em um Latossolo Vermelho Aluminoférrico. Frederico Westphalen, RS, 2014.

\begin{tabular}{|c|c|c|c|c|}
\hline \multirow{2}{*}{ Contrastes } & \multirow{2}{*}{$\begin{array}{l}\text { Produtividade de grãos } \\
-\mathrm{kg} \mathrm{ha}^{-1}\end{array}$} & \multicolumn{2}{|c|}{ Incremento de produtividade } & \multirow{2}{*}{$\begin{array}{c}\text { Significância } \\
-----p---- \\
\end{array}$} \\
\hline & & ---------- & ------\%"---- & \\
\hline $25 \times 0$ & $9.917 \times 8.488$ & $1.429^{*}$ & $16,83^{*}$ & 0,0013 \\
\hline $50 \times 0$ & $12.625 \times 8.488$ & $4.137 *$ & $48,74 *$ & $<0,0001$ \\
\hline $75 \times 0$ & $12.348 \times 8.488$ & $3.860^{*}$ & $45,47^{*}$ & $<0,0001$ \\
\hline $100 \times 0$ & $12.899 \times 8.488$ & $4.411 *$ & $51,97 *$ & $<0,0001$ \\
\hline $0 \times \mathrm{NPK}$ & $8.488 \times 12.591$ & $-4.103 *$ & $-32,59^{*}$ & $<0,0001$ \\
\hline $25 \times \mathrm{NPK}$ & $9.917 \times 12.591$ & $-2.674 *$ & $-21,23^{*}$ & $<0,0001$ \\
\hline $50 \times \mathrm{NPK}$ & $12.625 \times 12.591$ & ns & Ns & 0,9173 \\
\hline $75 \times \mathrm{NPK}$ & $12.348 \times 12.591$ & ns & Ns & 0,4686 \\
\hline $100 \times$ NPK & $12.899 \times 12.591$ & ns & Ns & 0,3617 \\
\hline
\end{tabular}

* Significativo pelo teste de contrastes ortogonais a $5 \%$ de probabilidade de erro. ns: não significativo.

Fonte: Elaboração dos autores.

Desta maneira, observou-se nesse trabalho que não ocorreu perdas de produtividade em relação à adubação mineral, para as doses de 50, 75 e 100 $\mathrm{m}^{3} \mathrm{ha}^{-1}$, onde suas médias demonstram que, nestas condições, a adubação com DLS contribui de forma positiva para o rendimento de grãos. Seidel et al. (2010) afirmam que o uso de DLS trata-se, de uma opção viável para o agricultor. Estes autores utilizaram, na cultura do milho, em um Latossolo Vermelho Distroférrico, adubação com doses de até $50 \mathrm{~m}^{3}$ ha $^{-1}$ e compararam com a adubação mineral, concluindo que a aplicação de DLS foi estatisticamente igual na produção de grãos de milho quando comparada com a adubação química. Os resultados neste estudo, em um Latossolo Vermelho Aluminoférrico, demonstram a eficácia da utilização de DLS, como fonte de nutrientes, e quando comparado com a fertilização mineral, possibilita ótimas produtividades de grãos da cultura do milho sob sistema de plantio direto. 


\section{Conclusões}

A adubação mineral na cultura do milho pode ser substituída por doses de dejetos líquidos de suínos a partir de $50 \mathrm{~m}^{3} \mathrm{ha}^{-1}$ em um Latossolo Vermelho de textura muito argilosa sem que haja prejuízos dos componentes de rendimento e não ocorrendo incremento significativo na produtividade de grãos a partir desta dose.

As doses de dejetos líquidos de suínos influenciaram diretamente as variáveis explicativas da cultura do milho. $\mathrm{O}$ aumento das doses de dejetos líquidos de suínos possibilitaram incrementos lineares no diâmetro das espigas e no peso de mil grãos de milho.

\section{Agradecimentos}

Ao CNPq, pela concessão de bolsa de iniciação científica e pelo apoio financeiro; e ao Colégio Agrícola de Frederico Westphalen, pela disponibilização dos dejetos líquidos de suínos.

\section{Referências}

AITA, C.; PORT, O.; GIACOMINI, S. J. Dinâmica do nitrogênio no solo e produção de fitomassa por plantas de cobertura no outono/inverno com o uso de dejetos de suínos. Revista Brasileira de Ciência do Solo, Viçosa, v. 30, n. 5, p. 901-910, out. 2006.

ANGERS, D. A.; CHANTIGNY, M. H.; MACDONALD, J. D.; ROCHETTE, P.; COTE, D. Differential retention of carbon, nitrogen and phosphorus in grassland soil profiles with long-term manure application. Nutrient Cycling in Agroecosystems, Heidelberg, v. 86, n. 2, p. 225-229, jun. 2010.

BARNABÉ, M. C.; ROSA, B.; LOPES, E. L.; ROCHA, G. P.; FREITAS, K. R.; PINHEIRO, E. P. Produção e composição químico-bromatológica da Brachiaria brizantha cv. marandu adubada com dejetos líquidos de suínos. Ciência Animal Brasileira, Goiânia, v. 8, n. 3, p. 435-446, jul./set. 2007.

BASSO, C. J.; CERETTA, C. A.; PAVINATO, P. S.; SILVEIRA, M. J. Perdas de nitrogênio de dejeto líquido de suínos por volatilização de amônia. Ciência Rural, Santa Maria, v. 34, n. 6, p. 1773-1778, nov./dez. 2004.
BERWANGER, A. L.; CERETTA, C. A.; SANTOS, D. R. Alterações no teor de fósforo no solo com aplicação de dejetos líquidos de suínos. Revista Brasileira da Ciência do Solo, Viçosa, MG, v. 32, n. 6, p. 2525-2532, nov./dez. 2008.

BORTOLINI, C. G.; SILVA, P. R. F.; ARGENTA, G.; FOSTHOFER, E. L. Rendimento de grãos de milho cultivado após aveia-preta em resposta a adubação nitrogenada em regime hídrico. Pesquisa Agropecuária Brasileira, Brasília, v. 36, n. 9, p. 1101-1106, mar./abr. 2001.

BRASIL. Ministério da Agricultura, Pecuária e Abastecimento. Regras para análise de sementes. Secretaria de Defesa Agropecuária, Brasília: MAPA/ ACS, 2009. 399 p.

CELA, S.; SANTIVERI, F.; LIOVERAS, J. Residual effects of pig slurry and mineral nitrogen fertilizer on irrigated wheat. European Journal of Agronomy, London, v. 34, n. 4, p. 257-262, maio 2011.

CERETTA, C. A.; DURIGON, R.; BASSO, C. J.; BARCELLOS, L. A. R.; VIEIRA, F. C. B. Características químicas de solo sob aplicação de esterco líquido de suínos em pastagem natural. Pesquisa Agropecuária Brasileira, Brasília, v. 38, n. 6, p. 729-735, jun. 2003.

CERETTA, C. A.; GIROTTO, E.; LOURENZI, C. R.; TRENTIN, G.; VIEIRA, R. C. B.; BRUNETTO, G. Nutrient transfer by runoff under no tillage in a soil treated with successive applications of pig slurry. Agriculture, Ecosystems and Environment, Amsterdam, v. 139, n. 4, p. 689-699, dez. 2010.

COELHO, A. M.; FRANÇA, G. E. Seja o doutor do seu milho: nutrição e adubação. Piracicaba: Informações Agronômicas, set. 1995. 25 p. (Arquivo do Agrônomo, n. 2).

COMISSÃO DE QUÍMICA E FERTILIDADE DO SOLO - CQFS-RS/SC. Manual de adubação e calagem para os estados do Rio Grande do Sul e Santa Catarina. 10. ed. Porto Alegre: Sociedade Brasileira de Ciência do Solo - Núcleo Regional Sul, 2004. 400 p.

FERrEIRA, A. C. D. B.; ARAÚJO, G. A. D. A.; PEREIRA, P. R. G.; CARDOSO, A. A. Características agronômicas e nutricionais do milho adubado com nitrogênio, molibdênio e zinco. Scientia Agricola, Piracicaba, v. 58, n. 1, p. 131-138, jan./mar. 2001.

FIXEN, P. E. Reservas mundiais de nutrientes dos fertilizantes. In: PROCHNOW, L. I. (Ed.). Informações agronomicas, 126. Piracicaba: International Plant Nutrition Institute, IPNI, jun. 2009. p. 8-14. 
GIACOMINI, S. J.; AITA, C. Cama sobreposta e dejetos líquidos de suínos como fonte de nitrogênio ao milho. Revista Brasileira Ciência do Solo, Viçosa, MG, v. 32, n. 1, p. 195-205, jan./fev. 2008.

GIACOMINI, S. J.; AITA, C.; CHIAPINOTTO, I. C.; HÜBNER, A. P.; MARQUES, M. G.; CADORE, F. Consorciação de plantas de cobertura no outono inverno como fonte de nitrogênio ao milho em sistema plantio direto: II. Potencial de fornecimento de nitrogênio. Revista Brasileira de Ciência do Solo, Viçosa, MG, v. 28, n. 4, p. 751-762, jul./ago. 2004.

GIACOMINI, S. J.; AITA, C.; JANTALIA, C. P.; URQUIAGA, S.; SANTOS, G. F. Imobilização do nitrogênio amoniacal de dejetos líquidos de suínos em plantio direto e preparo reduzido do solo. Revista Brasileira Ciência do Solo, Viçosa, MG, v. 33, n. 1, p. 41-50, jan./fev. 2009.

KAMPF, N.; GIASSON, E.; INDA JUNIOR, A. V.; NASCIMENTO, P. C.; RODRIGUES, A. L. M.; ANGHINIONI, M. C. M.; FERRARO, L. W.; BINOTTO, R. B.; SANBERG, J. R. D. Metodologia para classificação de solos quanto à resistência a impactos ambientais decorrentes da disposição final de resíduos. FEPAM em revista, Porto Alegre, v. 2, n. 1, p. 11-17, jan./ dez. 2008.

KAPPES, C.; CARVALHO, M. A. C.; YAMASHITA, O. M.; SILVA, J. A. N. Influência do nitrogênio no desempenho produtivo do milho cultivado na segunda safra em sucessão à soja. Pesquisa Agropecuária Tropical, Goiânia, v. 39, n. 3, p. 251-259, jul./set. 2009.

LEITE, G. F.; CUNHA NETO, F. R.; RESENDE, A. V. Produtividade agrícola da cana-de-açúcar adubada com dejetos líquidos de suínos. Ciências Agrotecnicas, Lavras, v. 33, n. 1, p. 132-138, jan./fev. 2009.

LOPES, S. J.; LÚCIO, A. D. C.; STORCK, L.; DAMO, H. P.; BRUM, B.; SANTOS, V. J. Relações de causa e efeito em espigas de milho relacionadas aos tipos de híbridos. Ciência Rural, v. 37, n. 6, p. 1536-1542, nov./ dez. 2007.

MOTA, F. S. Meteorología agrícola. 5. ed. São Paulo: Nobel, 1981. $376 \mathrm{p}$.

MUNDSTOCK, C. M.; SILVA, P. R. F. Manejo da cultura do milho para altos rendimentos de grãos. Porto Alegre: Departamento de Plantas de Lavoura da Universidade Federal do Rio Grande do Sul, 2005. 51 p.
QUEIROZ, A.; MARTINS, D.; SOUZA, C. H. E. D.; MACHADO, V. J.; LANA, R.; KORNDORFER, G. H.; SILVA, A. D. A. Avaliação de diferentes fontes e doses de nitrogênio na adubação da cultura do milho (Zea mays L.). Revista Brasileira de Milho e Sorgo, Sete Lagoas, v. 10, n. 3, p. 257-266, jul./set. 2011.

RAMBO, L.; SILVA, P. R. F.; STRIEDER, M. L.; DELATORRE, C. A.; BAYER, C.; ARGENTA, G. Adequação e doses de nitrogênio em milho com base em indicadores de solo e de planta. Pesquisa Agropecuária Brasileira, Brasília, v. 43, n. 3, p. 401-409, mar. 2008.

SANTOS, H. G.; JACOMINE, P. K. T.; ANJOS, L. H. C.; OLIVEIRA, V. A.; LUBRERAS, J. F.; COELHO, M. R.; ALMEIDA, J. A.; CUNHA, T. J. F.; OLIVEIRA, J. B. (Ed.). Sistema brasileiro de classificação de solos. 3. ed. rev. ampl. Brasília: Embrapa, 2013. 353 p.

SARTOR, L. R.; ASSMANN, AL. L.; ASSMANN, P. E. B.; MIYAZAWA, M.; CARVALHO, P. C. F. Effect of swine residue rates on corn, common bean, soybean and wheat yield. Revista Brasileira de Ciência do Solo, Viçosa, MG, v. 36, n. 2, p. 661-669, mar./abr. 2012.

SCHERER, E. E.; BALDISSERA, I. T.; DIAS, L. F. $X$. Método rápido para determinação da qualidade fertilizante do esterco de suínos a campo. Revista Agropecuária Catarinense, Florianópolis, v. 8, n. 2, p. 40-43, abr./jun. 1995.

SEDIYAMA, M. A. N.; GARCIA, N. C. P.; VIDIGAL, S. M.; MATOS, A. D. Nutrients in organic composts of plant residues and swine manure. Scientia Agricola, Piracicaba, v. 57, n. 1, p. 185-189, jan./mar. 2000.

SEIDEL, E. P.; GONÇALVES JUNIOR, A. C.; VANIN, J. P.; STREY, L.; SCHWANTES, D.; NACKE, H. Aplicação de dejetos de suínos na cultura do milho cultivado em sistema de plantio direto. Acta Scientiarum. Technology, Maringá, v. 32, n. 2, p. 113-117, maio/jun. 2010.

SERPA FILHO, R.; SEHNEM, S.; CERICATO, A.; SANTOS JUNIOR, S.; FISCHER, A. Compostagem de dejetos de suínos. Revista em Agronegócios e Meio Ambiente, Maringá, v. 6, n. 1, p. 47-78, jan./abr. 2013.

VON PINHO, R. G.; RIVERA, A. A. C.; BRITO, A. H.; LIMA, T. G. Avaliação agronômica do cultivo de milho em diferentes níveis de investimento. Ciências Agrotecnicas, Lavras, v. 33, n. 1, p. 39-46, jan./fev. 2009.

YAGÜE, M. R.; QUÍLEZ, D. Direct and residual response of wheat to swine slurry application method. Nutrient Cycling in Agroecosystems, Heidelberg, v. 86, n. 1, p. 161-174, jan. 2010. 